AperTO - Archivio Istituzionale Open Access dell'Università di Torino

\title{
Pericyte Loss in Diabetic Retinopathy: Mechanisms and Consequences
}

\section{This is the author's manuscript}

Original Citation:

Availability:

This version is available http://hdl.handle.net/2318/137761

since

Published version:

DOI:10.2174/09298673113209990022

Terms of use:

Open Access

Anyone can freely access the full text of works made available as "Open Access". Works made available under a Creative Commons license can be used according to the terms and conditions of said license. Use of all other works requires consent of the right holder (author or publisher) if not exempted from copyright protection by the applicable law. 


\title{
(1) \\ UNIVERSITÀ DEGLI STUDI DI TORINO
}

This is an author version of the contribution published on:

\author{
Beltramo E, Porta M
}

Pericyte Loss in Diabetic Retinopathy: Mechanisms and Consequences

CURRENT MEDICINAL CHEMISTRY (2013) 20

DOI: $10.2174 / 09298673113209990022$

The definitive version is available at:

http://www.eurekaselect.com/113178/article 


\section{Elena Beltramo and Massimo Porta \\ Dept of Medical Sciences, University of Turin}

Pericyte Loss in Diabetic Retinopathy: Mechanisms and Consequences

Running Header: Pericyte loss in Diabetic Retinopathy

\section{Corresponding Authors:}

Elena Beltramo, MSc PhD

Dept of Medical Sciences - University of Turin

Corso Dogliotti, 14

10126 Torino - Italy

Tel: +39.011 .6708471$

Fax: +39.011 .2368471$

elena.beltramo@unito.it

Massimo Porta, MD PhD

Dept of Medical Sciences - University of Turin

Corso Dogliotti, 14

10126 Torino - Italy

Tel: +39.011 .6632354$

Fax: +39.011 .6708477$

massimo.porta@unito.it

Keywords: Apoptosis, Diabetic Retinopathy, Endothelial cells, Extracellular matrix, Pericytes, Pericyte loss. 


\begin{abstract}
The onset of diabetic retinopathy is characterized by morphologic alterations of the microvessels, with thickening of the basement membrane, loss of inter-endothelial tight junctions and early and selective loss of pericytes, together with increased vascular permeability, capillary occlusions, microaneurysms and, later, loss of endothelial cells. A key role in the evolution of the disease is played by pericytes, specialized contractile mesenchymal cells of mesodermal origin, that, in capillaries, exert a function similar to smooth muscle cells in larger vessels, regulating vascular tone and perfusion pressure. Thickening of the basement membrane, together with systemic and local hypertension, hyperglycaemia, advanced glycation end-product formation and hypoxia, may disrupt the tight link between pericytes and EC causing pericyte apoptosis, while endothelium, deprived of proliferation control, can give rise to new vessels. Pericyte dropout has great consequences on capillary remodelling and may cause the first abnormalities of the diabetic eye which can be observed clinically. Hyperglycaemia and local hypertension are known to be a direct cause of pericyte apoptosis and dropout, and intracellular biochemical pathways of the glucose metabolites have been explored. However, the exact mechanisms are not yet fully understood and need further clarification in order to develop new effective drugs for the prevention of retinopathy.
\end{abstract}




\section{Introduction}

Generalized increase of capillary blood flow and vasodilatation are among the first features observed at onset of diabetes. Subsequently, morphologic alterations of the microvessels are described, especially in the retinal district, where the early phases of diabetic retinopathy (DR) are characterized by thickening of the basement membrane, loss of inter-endothelial tight junctions and early and selective loss of pericytes, together with increased vascular permeability, capillary occlusions, microaneurysms and, later, loss of endothelial cells (EC) $[1,2]$. Endothelium plays a complex role in the regulation of the vessel tone, the maintenance of the coagulation balance and the modulation of platelet activation. It also regulates the metabolism of the basement membrane, vascular permeability, migration of leucocytes and macromolecules from the vessel lumen to the sub-endothelium and vice versa $[3,4]$.

However, a key role in the evolution of this complication of diabetes is played by the other capillary cell type, the pericyte, a specialized contractile mesenchymal cell of mesodermal origin which exerts in capillaries a function similar to that of smooth muscle cells (SMC) in larger vessels, regulating vascular tone and perfusion pressure [5]. Retinal capillary vessels are composed of a 1:1 ratio of EC and pericytes, the highest in the whole body [6], with pericytes closely linked to EC through gap-junctions [7] and playing a role in the regulation of their proliferation, while receiving nourishment and growth factors from them [5]. Thickening of the basement membrane during the first phases of DR, together with systemic and local hypertension, hyperglycaemia, advanced glycation end-product (AGE) formation and hypoxia may all disrupt this link and cause pericyte apoptosis and drop-out, while endothelium, deprived of proliferation control, can initiate to proliferate in microaneurysms in the early phases and, eventually, new vessels in later stages of retinopathy [6]. Pericyte dropout has great consequences on capillary remodelling and may cause the first abnormalities of the diabetic eye which can be observed clinically. 


\section{The pericyte: morphology and function}

Pericytes are ubiquitous, pluripotent, mesenchymal cells which derive from the neural crest during the embryonic development [8] and mediate physiological and pathological repair processes [9]. They were first described by Rouget in 1873 [10] and named by Zimmerman in 1923 [11]. Cogan and Kubawara in 1961 [12, 13] for the first time associated them with diabetic retinopathy.

Pericytes have several similarities with SMC, first of all their contractile properties, and share with them common markers ( $\alpha$-smooth muscle actin and desmin) [14]. Other markers commonly used to identify these cells are the proteoglycan NG2 and PDGF-R $\beta$ [15]; however, it has been demonstrated that none of them is able to recognize pericytes at all stages and in all contexts [5].

A common precursor for pericytes and SMC in the development of the retina has been identified in a mural precursor cell type, positive for desmin and NG2 (a marker for both immature smooth muscle cells and pericytes) and present on undifferentiated vessels. After birth, this cell type differentiates to pericytes or SMC [16]. Possible derivation of pericytes from a trans-differentiation of EC to repair vessel wounds [17] and/or from bone marrow to support adult angiogenesis [18] has been also postulated. Several studies have underlined a strict relationship between mesenchymal stem cells (MSC) and pericytes. In fact, pericytes in their tissue of origin natively express the MSC markers CD44, CD90, CD73 and CD105 [19, 20]; cells expressing MSC markers, express also pericyte ones ( $\alpha$-smooth muscle actin, NG2 and PDGF-R $\beta$ ) [21] and pericyte clones have osteogenic, chondrogenic, adipocytic and myogenic properties, characteristic of MSC [22]. Moreover, bone marrow-derived MSC injected in rats with glioblastoma migrate around the vessels and differentiate into pericytes, as demonstrated by phenotype expression of the typical pericyte markers, and not EC ones [23].

Pericytes are present in the capillaries of all districts in the body with a role of support of the microvasculature. However, their density is rather variable, ranging from 1:100 (pericyte:EC) in the cardiac and skeletal muscle to 1:1 in the retina [24]. The reason for this high ratio is the need for an extremely high barrier function in the retina itself, to preserve it from extra fluid deposition that could lead to visual loss [25]. Pericytes have a prominent nucleus and long cytoplasmic processes, some of which embrace the vessel wall while others run parallel to the axis of the capillary itself or protrude to reach other capillaries [25]; these processes mediate pericyte-pericyte, pericyte-EC and pericyteretinal neuroglia cell-to-cell communications [15]. In the retina, pericytes live in pockets embedded within the basement membrane (intramural pericytes) [26] and participate to its anabolism by producing glycoproteins (especially collagen) and glycosaminoglycans [27]; they surround the ECs which form the capillary tube and stabilize the vessel.

The contractile phenotype of pericytes, in addition to the presence of contractile proteins (smooth muscle and nonsmooth muscle isoforms of actin and myosin), is confirmed by their response to a series of paracrine molecules which regulate their contractility, both vasoconstrictors, such as angiotensin II, endothelin-1, $\alpha_{2}$-adrenergic agonists, and vasodilators, such as $\mathrm{NO}$ and $\beta_{2}$-adrenergic agonists [28]. In the brain and the retina pericyte contractility is induced by a rise in extracellular $\mathrm{Ca}^{2+}$ concentrations and the signal can sometimes propagate to reach distant pericytes [29]; on the other hand, it is demonstrated that calcium-activated intracellular cascades play key roles in the different steps of angiogenesis [30]. 


\section{Pericyte-endothelial cell interactions}

Pericytes are closely linked to EC through tight junctions, gap junctions, adhesion plaques, and peg and socket contacts [31] with continuous exchange of nucleotides and small molecules [32]. Interactions between the two cell types are also mediated by cell adhesion molecules secreted by both, whose imbalance may cause leakage of the blood barrier during the early phases of DR [15]. Tight junction proteins (such as claudins and occludins), interconnecting pericytes and EC, are structural components of the blood-retinal barrier [33] while it is through the gap junctions, membrane channels directly connecting the cytoplasms of the two cell types, that pericytes exert a key role in the regulation of EC proliferation during physiological angiogenesis [34]. Adhesion plaques, rich in fibronectin, are responsible for the anchorage of the pericyte to the endothelium during contraction or propagation of the shear stress [35].

Pericyte coverage is required for the stabilization of immature endothelial tubes [36], and vascular endothelial growth factor (VEGF), angiopoietin-2 (Ang-2), Transforming Growth Factor- $\beta$ (TGF- $\beta$ ), PDGF-B and metalloproteinases are among the required factors for the survival and/or recruitment and differentiation of pericytes. In particular, PDGF-B, secreted by endothelium, and its receptor PDGFR- $\beta$ (expressed in pericytes only) [37] are important in the proliferation, migration and recruitment of pericytes to the vasculature during retinal development and in the stabilization of newly-formed vessels [38, 39]. Pericyte-produced VEGF stimulates EC proliferation, and the interaction EC-pericyte is responsible for the activation of TGF- $\beta$, which induces the differentiation of pericytes, while inhibiting EC proliferation and migration, thanks to its involvement in the interactions between microvascular cells and ECM [15]. Angiopoietin-1 is secreted by pericytes and acts on ECs through its receptor Tie2, stabilizing vessels and reducing permeability, while, in contrast, Ang-2 increases permeability. On the other hand, it has been shown that Ang2 in combination with VEGF induces angiogenesis while, in the absence of VEGF, it causes vessel regression [40]. The proliferation control exerted by pericytes on EC is mediated by soluble factors able to upregulate endothelin-1 and downregulate iNOS production [41].

Besides endothelium, pericytes is also in contact with Müller cells, the main retinal glial cells, which contribute to the stability of the blood-retinal barrier and the maintenance of retinal homeostasis. Müller cells have been shown to protect both neurons and pericytes from damage caused by hyperglycaemia-induced reactive oxygen species (ROS) (see below) [42].

\section{Pericyte loss during DR: evidences and clinical consequences}

Early pericyte loss is a recognized hallmark of DR [13]. The so-called "pericyte ghosts", empty pockets within the basement membrane of a viable capillary formerly occupied by the pericytes themselves, a common feature of the early phases of the disease, are characteristic of the retina while they are rare or absent in the capillaries of the optic nerve and cerebral cortex [43]. Together with later loss of EC, pericyte disappearance provokes the formation of acellular capillaries (i.e. tubes formed by basement membrane only), capillary occlusion and formation of microaneurysms, the first clinically relevant lesion in the diabetic eye. Progressive vessel occlusion is followed by increased permeability, partly due to VEGF over-expression [44], which also induces intravessel EC proliferation and, eventually, neovascolarization, with consequent hemorrhages and visual loss [45] (Fig. 1). 


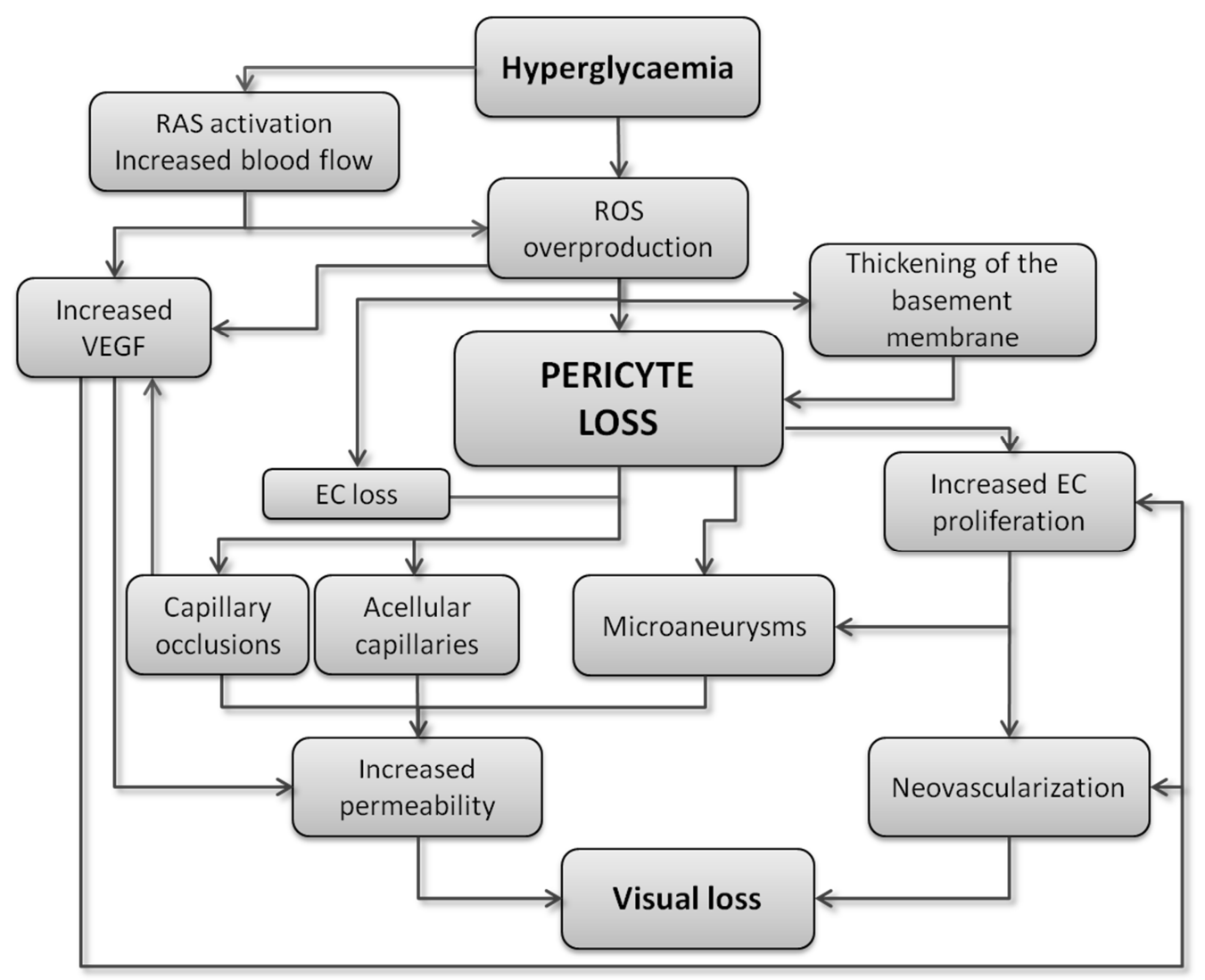

Fig. 1. Mechanisms and consequences of pericyte loss in the pathogenesis of diabetic retinopathy.

Although pericyte disappearance in the first phases of DR is widely understood to be the result of direct hyperglycaemic damage, the exact mechanisms underlying their degeneration are still unclear. High glucose levels, in vitro as well as in vivo, induce pericyte apoptosis [46-50], leading to the well-known alterations of retinal capillaries. In particular, human retinal pericytes (HRP) are highly-susceptible to fluctuating glucose levels, rather than stable exposure to high glucose conditions [51, 52]. Intermittent exposure to high glucose has been described to increase apoptosis related to oxidative stress also in EC [53-56] and a ROS - mediated cell "memory" of vascular stress after glucose normalization has been shown in human EC and in the human retinal pigment epithelial cell line, ARPE-19 [56]. These findings are consistent with the clinical observation that daily fluctuations in plasma glucose concentrations, such as they occur in diabetic patients, are correlated to increased risk of cardiovascular disease [57] and microvascular complications [58]. Hyperglycaemia impairs retinal vessel autoregulation in humans [59], therefore pericytes are likely to be exposed to an increased mechanical insult secondary to systemic and capillary hypertension. Contraction and relaxation of pericytes is thought to regulate the luminal diameter of retinal capillaries and these cells are believed to play a major role in adjusting blood flow through the retinal capillary bed [60], as described above: the contractile phenotype of pericytes is thus an important determinant of the haemodynamic stress experienced by retinal capillaries. It has been showed that mechanical stretch, alone or combined with high glucose, reduces cell proliferation, increases apoptosis and induces morphological changes in the pericyte cytoskeleton [61].

Autoregulation of the vessel tone is impaired from the first phases of diabetes due to hyperglycaemia, with different haemodynamic alterations characteristics of the evolution of the disease. Initially, the blood flow increases in several vascular districts, particularly in the retina [62] and glomerulus, due to a strict correlation between the arteriolar vasodilatation and the high blood glucose concentrations [63]. In a second phase, endothelium seems to lose its ability 
to induce vasodilatation, due to impaired balance between vasoconstrictors, such as endothelin-1, and vasodilators, such as NO, the concentrations of which are reduced [64].

Reduced adhesion and increased apoptosis in pericytes seeded on extracellular matrix (ECM) produced by EC cultured in high glucose concentrations, possibly due to glycation of the matrix proteins, have been described [51, 65, 66]. Since the ultrastructural analysis of retinal microaneurysms shows the absence of pericytes, impaired vessel integrity after pericyte loss could make the capillary wall more susceptible to dilatation, leading to microaneurysms; moreover, the correlation between pericyte absence and retinal neovascolarization may indirectly confirm the role of pericytes in the inhibition of the capillary growth [6, 35, 67]. The impaired cell-to-cell and cell-to-ECM interactions are also due to alterations to the molecules mediating these contacts: thickening of the basement membrane derives from a process involving hyperglycemia-induced excess synthesis of components of the basement membrane itself, such as fibronectin, collagen type IV and laminin [68, 69], together with increased integrin expression [70]. In contrast with what happens with pericytes, increased integrin expression and fibronectin production seem to correlate with greater EC/ECM adhesion [71, 72]. This may negatively influence EC proliferation through the induction of cytoskeleton modifications [73] in the later phases of DR. Recently, it has been suggested that a long-term strategy based upon small interference RNA (RNA sequences which interferes with the expression of specific genes through complementary nucleotide sequence) may regulate fibronectin overexpression and improve vascular lesions in retinas of diabetic rats [74].

Capillary occlusion is probably caused by the complex of the alterations above mentioned: increased vascular tone, thickening of the basement membrane, loss of pericytes and EC with formation of acellular capillaries and obstruction of the vessel lumen, due to leucocyte adhesion and platelet aggregation. Ischemia and hypoxia resulting from capillary occlusion lead to an angiogenic response to compensate for the reduction of the blood flow downstream of the occlusion [75].

As described above, pericyte coverage is essential for the stabilization of immature endothelial tubes. PDGF-B and PDGFR- $\beta$ are important in the proliferation, migration and recruitment of pericytes to the vasculature during retinal development and in the stabilization of newly-formed vessels [38, 39] and seem to play a key role in the mechanisms underlying vascular changes in DR [15]. Pericytes, but not endothelial cells, express PDGFR- $\beta$ in vivo [37, 38]. In diabetic mouse retinas, PDGF-B mRNA is decreased in comparison with non-diabetic mice, suggesting a role for PDGF-B in hyperglycaemia-induced pericyte loss [37]. Retinas of mice with endothelium-restricted ablation of PDGFB showed that up to $50 \%$ pericyte loss is accompanied by vasoregression, while pericyte reduction exceeding $50 \%$ induces retinal vasoproliferation mimicking PDR [37, 38].

\section{Pericyte loss during DR: the renin-angiotensin system}

The severity of vascular complications in diabetes has been associated not only with the duration and degree of hyperglycaemia, but also with those of hypertension [76, 77] (Fig. 1).

The renin-angiotensin system (RAS), an endocrine system that, at a systemic level, regulate blood pression and electrolyte homeostasis, some twenty years ago has been described to be present also locally, with differences among the various tissues [78]. In particular, local RAS are present in the organs mainly affected by diabetes, such as kidney, peripheral nerves and the eye [79]. All components of the RAS system have been described in the neural retina, as well as in the capillaries [80]. In diabetes, RAS is upregulated, hyperglycemia increasing the transcription of angiotensinogen and the production of angiotensin II, the most important end-product of the RAS system, which binds to both angiotensin type $1\left(\mathrm{AT}_{1} \mathrm{R}\right)$ and type 2 receptors $\left(\mathrm{AT}_{2} \mathrm{R}\right)$ [81]. 
In the eye, RAS contributes to the diabetes-induced damage through two different mechanisms: the over-activation of $\mathrm{AT}_{1} \mathrm{R}$ by high levels of angiotensin II increases VEGF expression in pericytes, leading to vascular leakage [82], pericyte-mediated vasoconstriction [83], oxidative stress [84], thickening of the basement membrane [85] and NF- $\kappa \mathrm{B}$ activation [86]. Moreover, RAS has been described to play a role in several of the biochemical dysfunctions described in the following paragraph, which are directly induced by hyperglycaemia: angiotensin II increases AGE formation [87], protein kinase C (PKC) synthesis [88] and ROS production [82], and enhances the flux through the polyol pathway [89], while hyperglycaemia induces angiotensinogen gene expression through the hexosamine pathway [90]. There is evidence to indicate that blockade of RAS confers retinal protection in experimental models of DR and ischemic retinopathy, ameliorating retinal hyperpermeability [91] and restoring blood flow [92]. Recently, it has been demonstrated that the angiotensin converting enzyme (ACE) inhibitor captopril can block capillary degeneration in the early stages of DR, inhibiting hyperglycemia-induced acellular capillary formation and pericyte ghosts [93]. At a clinical level, blockade of the RAS, through the ACE inhibitor lisinopril, has been shown to reduce both incidence and progression of DR in type 1 diabetes [94], while results from the DIabetic Retinopathy Candesartan Trials (DIRECT) show that the $\mathrm{AT}_{1} \mathrm{R}$ blocker candesartan during a 4 year trial was able to reduce the incidence of retinopathy in patients with type 1 diabetes [95] and determine a regression of DR in type 2 diabetic patients [96].

\section{Pericyte loss during DR: glucose metabolism pathways}

Chronic hyperglycaemia and daily fluctuations in blood glucose have been clearly associated to the severity of microvascular complications and it is widely acknowledged that pericyte loss in the first phases of DR is the result of direct hyperglycaemic damage.

It is possible to discriminate between two different types of mechanisms involved in glucose-mediated damage: while the former induces acute but reversible metabolic changes, the latter causes a cumulative damage that sometimes even worsens if glycaemia is rapidly restored to physiological levels [97].

Vascular cells have been widely reported to be sensible to direct exposure to high glucose concentrations [49, 98, 99], their increased apoptosis being correlated to increased expression of the pro-apoptotic Bax proteins in vivo and in vitro [99] and activation of NF- $\mathrm{B}$ in vitro [48]. However, as already mentioned, human retinal pericytes seem to be more sensible to intermittent than stable high glucose concentrations, due to impairment in the Bcl-2/Bax ratio [51, 52], while rapid glucose normalization, explained as "ROS - mediated cellular memory" of vascular stress has been shown in EC and retinal ARPE-19 [56], consistently with the clinical observation that daily fluctuations in plasma glucose concentrations in diabetic patients are related to increased risk of cardiovascular disease [57] and microvascular complications [58]. DR itself has been seen to accelerate after restoration of physiological glycaemic levels, mostly if glycaemic control is rapidly achieved [100-103].

A possible explanation to hyperglycaemic damage to microvascular cells, and pericytes in particular, is the involvement of four major biochemical pathways: 1. increased flux through the polyol pathway; 2 . increased formation of advanced glycation end-products (AGE); 3. activation of the protein kinase $\mathrm{C}$; 4. increased flux through the hexosamine pathway $[15,104]$.

1. Aldose-reductase, the key-enzyme of the polyol pathway, reduces toxic aldehydes to inactive alcohols in physiological conditions. However, in the case of excess intracellular glucose, aldose-reductase converts it to sorbitol, consuming NADPH and giving rise to a sort of hyperglycaemic pseudohypoxia [105], together with an increased susceptibility to intracellular oxidative stress [106, 107]. 
2. Excess intracellular glucose is able to react with proteins, amino acids and nucleic acids via Schiff base condensation, this initial reaction being followed by irreversible rearrangement into an Amadori product. AGE may be produced ex-novo by a slower Maillard reaction or directly derive from these early products through glycoxidation reactions or reactive dicarbonyl fragments generated from free glucose [108]. AGE are toxic products which can modify intracellular proteins, including those involved in the regulation of gene transcription [109], or diffuse outside the cell modifying the extracellular matrix [110], with consequent reduction of the cell-tocell adhesion and vascular dysfunction [65, 66], and also modify circulating blood proteins, inducing production of inflammatory cytokines and growth factors $[111,112]$.

3. High glucose concentrations inside the cell also activate PKC synthesis through de novo synthesis of the lipid second messenger diacylglycerol (DAG) [113]. This may lead to decreased synthesis of endothelial nitric oxide synthase (eNOS), increased synthesis of endothelin-1, TGF- $\beta$, plasminogen activator inhibitor-1 [114] and NF-אB [115].

4. Finally, high availability of intracellular glucose leads to an excess of fructose-6-phosphate which is transformed to glucosamine-6-phosphate and then UDP $N$-acetyl-glucosamine; the latter acts on serine and threonine residues of transcription factors, giving rise to pathological changes in gene expression [116, 117].

A common denominator of these apparently independent biochemical pathways, the so-called "unifying mechanism", was identified by Brownlee and co-workers in excess ROS production by the mitochondria, induced by high glucose as a result of increased flux through the Krebs' cycle [115]. ROS would activate the poly-(ADP-ribose)-polymerase (PARP), which in turn inhibits glyceraldehyde-phosphate-dehydrogenase (GAPDH) activity [118], therefore pushing metabolites from glycolysis in the upstream pathways mentioned above.

Evidence in the literature shows that oxidative stress, implicated in pericyte loss, may be induced also by extravasated, modified plasma LDL, present in the diabetic but not the healthy retina [119, 120].

\section{New hypothesis for pericyte loss involvement in the pathogenesis of DR}

Recent findings hypothesize that some pericytes, having lost contact with their original capillaries, do not undergo apoptosis, but migrate to other capillaries or into the perivascular space. Ang-2 overexpression, induced by excess AGE in the hyperglycaemic milieu, may play a key role in this process, since Ang-2 deficient mice did not show any migration in the presence of hyperglycaemia [121].

High glucose was reported to induce mitochondrial fragmentation and dysfunction in retinal endothelial cells, contributing to apoptosis. Recently, it has been demonstrated that, in hyperglycaemic-like conditions, mitochondria of retinal pericytes also show fragmentation, metabolic dysfunction and reduced extracellular acidification [122].

It has also been suggested that pericyte are immunosuppressive and protect EC from inflammation-mediated apoptosis. Hyperglycemic conditions may impair their $\mathrm{T}$ cell inhibitory activity, favouring retinal inflammation and contributing to the pathogenesis of DR [123].

Another recent work verified the hypothesis that auto-antibodies against pericytes could develop in DR, inducing retinal pericyte dysfunction or eventually death through complement activation [124]. 


\section{Conclusions}

Early pericyte dropout and apoptosis are among the earliest events in the natural history of diabetic retinopathy. Hyperglycaemia and hypertension have been correlated to this disappearance but the exact mechanisms are not yet fully understood. Thickening of the basement membrane, also occurring in the first phases of retinopathy, may contribute to disrupt the tight connections between pericytes and endothelial cells, impairing their reciprocal, fine-controlled balance. Without the proliferation control exerted by pericytes, EC are free to duplicate, giving rise to angiogenesis and leading to the advanced phases of diabetic retinopathy.

Despite advancements in ophthalmic care and management of both type 1 and type 2 diabetes, proliferative diabetic retinopathy and diabetic macular oedema remain leading causes of blindness, for which at the moment there are no specific forms of prevention, apart from the day to day struggle of keeping blood glucose and pressure under optimal control. Even so, the onset and progression of retinopathy are delayed but not entirely prevented. Therefore, there is a need for alternative, low cost pharmacologic approaches which should be addressed towards the mechanisms presiding over of the first key events of the disease, and pericyte loss may well be an important one.

\section{Conflict of Interest}

The Authors declare no conflict of interest. 


\section{References}

[1] Porta, M. Endothelium: the main actor in the remodelling of the retinal microvasculature in diabetes. Diabetologia, 1996; 39, 739-744.

[2] Schalkwijk, C.G.; Stehouwer, C.D. Vascular complications in diabetes mellitus: the role of endothelial dysfunction. Clin. Sci. (Lond), 2005, 109(2), 143-159.

[3] Cines, D.B.; Pollak, E.S.; Buck, C.A.; Loscalzo, J.; Zimmerman, G.A.; McEver, R.P.; Pober, J.S.; Wick, T.M.; Konkle, B.A.; Schwartz, B.S.; Barnathan, E.S.; McCrae, K.R.; Hug, B.A.; Schmidt, A.M.; Stern, D.M. Endothelial cells in physiology and in the pathophysiology of vascular disorders. Blood, 1998, 91, 3527-3561.

[4] Tsilibary, E.C. Microvascular basement membranes in diabetes mellitus. J. Pathol., 2003, 200, 537-546.

[5] Armulik, A.; Abramsson, A; Betsholtz, C. Endothelial/pericyte interactions. Circ. Res., 2005, 97, $512-523$.

[6] Hammes, H.P. Pericytes and the pathogenesis of diabetic retinopathy. Horm. Metab. Res., 2005, 37 (Suppl. 1), 39 43.

[7] Chakravarthy, U.; Gardiner, T.A. Endothelium-derived agents in pericyte function/dysfunction. Prog. Retin. Eye Res., 1999, 18, 511-527.

[8] Etchevers, H.C.; Vincent, C.; Le Douarin, N.M.; Couly, G.F. The cephalic neural crest provides pericytes and smooth muscle cells to all blood vessels of the face and forebrain. Development, 2001, 128, 1059-1068.

[9] Hayden, M.R.; Yang, Y.; Habibi, J.; Bagree, S.V.; Sowers, J.R. Pericytopathy: oxidative stress and impaired cellular longevity in the pancreas and skeletal muscle in metabolic syndrome and type 2 diabetes. Oxid. Med. Cell. Longev., 2010, 3, 290-303.

[10] Rouget, C. Mémoire sur les développement, la structure et les propriétés physiologiques des capillaires sanguins et lymphatiques. Arch. Physiol. Norm. Pathol., 1873, 5, 603-633.

[11] Zimmerman, K.W. Der feinere Bau der Blut capillaren. Z. Anat. Entwicklungsgesch, 1923, 68, 3-109.

[12] Kubawara, T.; Carroll, J.M.; Cogan, D.G. Retinal vascular patterns. III. Age, hypertension, absolute glaucoma, injury. Arch. Ophthalmol., 1961, 65, 708-716.

[13] Cogan, D.; Toussaint, D.; Kubawara, T. Retinal vascular patterns. IV. Diabetic retinopathy. Arch. Ophthalmol., 1961, 66, 366-378.

[14] Sims, D.E. Diversity within pericytes. Clin. Exp. Pharmacol. Physiol., 2000, 27: 842-846.

[15] Pfister, F.; Lin, J.; Hammes, H.P. Pericyte Loss in the Diabetic Retina. In: Experimental Approaches to Diabetic Retinopathy; Hammes, H.P.; Porta, M. Eds.; Front Diabetes, Karger: Basel, 2010; Vol. 20, pp. 61-78.

[16] Hughes, S.; Chan-Ling, T. Characterization of smooth muscle cell and pericyte differentiation in the rat retina in vivo. Invest. Ophthalmol. Vis. Sci., 2004, 45, 2795-2806.

[17] DeRuiter, M.C.; Poelmann, R.E.; VanMunsteren, J.C.; Mironov, V.; Markwald, R.R.; Gittenberger-de-Groot, A.C. Embryonic endothelial cells transdifferentiate into mesenchymal cells expressing smooth muscle actins in vivo and in vitro. Circ. Res., 1997, 80, 444-451.

[18] Rajantie, I.; Ilmonen, M.; Alminaite, A.; Ozerdem, U.; Alitalo, K.; Salven, P. Adult bone marrow-derived cells recruited during angiogenesis comprise precursors for periendothelial vascular mural cells. Blood, 2004, 1, 104, 2084-2086.

[19] Schwab, K.E.; Gargett, C.E. Co-expression of two perivascular cell markers isolates mesenchymal stem-like cells from human endometrium. Hum. Reprod., 2007, 22, 2903-2911.

[20] Crisan, M.; Yap, S.; Casteilla, L.; Chen, C.W.; Corselli, M.; Park, T.S.; Andriolo, G.; Sun, B.; Zheng, B.; Zhang, L.; Norotte, C.; Teng, P.N.; Traas, J.; Schugar, R.; Deasy, B.M.; Badylak, S.; Buhring, H.J.; Giacobino, J.P.; Lazzari, L.; Huard, J.; Péault, B. A perivascular origin for mesenchymal stem cells in multiple human organs. Cell Stem Cell, 2008, 3, 301-313.

[21] Corselli, M.; Chen, C.W.; Crisan, M.; Lazzari, L.; Péault, B. Perivascular ancestors of adult multipotent stem cells. Arterioscler. Thromb. Vasc. Biol., 2010, 30, 1104-1109.

[22] Caplan, A.I. All MSCs are pericytes? Cell Stem Cell, 2008, 3, 229-230.

[23] Bexell, D.; Gunnarsson, S.; Tormin, A.; Darabi, A.; Gisselsson, D.; Roybon, L.; Scheding, S.; Bengzon, J. Bone marrow multipotent mesenchymal stroma cells act as pericyte-like migratory vehicles in experimental gliomas. Mol. Ther., 2009, 17, 183-190.

[24] Sims, D.E. Recent advances in pericyte biology. Implications for health and disease. Can. J. Cardiol., 1991, 7, 431-443.

[25] Shepro, D.; Morel, N.M. Pericyte physiology. FASEB J., 1993, 7:1031-1038.

[26] Sims, D.E. The pericyte: a review. Tissue Cell, 1986, 18:153-174. 
[27] Canfield, A.E.; Allen, T.D., Grant, M.E.; Schor, S.L.; Schor, A.M. Modulation of extracellular matrix biosynthesis by bovine retinal pericytes in vitro: effects of the substratum and cell density. J. Cell. Sci., 1990, 96 (Pt 1), 159-169.

[28] Rucker, H.K.; Wynder, H.J.; Thomas, W.E. Cellular mechanisms of CNS pericytes. Brain Res. Bull., 2000, 51, 363-369.

[29] Peppiatt, C.M.; Howarth, C.; Mobbs, P.; Attwell, D. Bidirectional control of CNS capillary diameter by pericytes. Nature, 2006, 443, 700-704.

[30] Munaron, L.; Fiorio Pla A. Endothelial calcium machinery and angiogenesis: understanding physiology to interfere with pathology. Curr. Med. Chem., 2009, 16, 4691-4703.

[31] Ueno, M. Molecular anatomy of the brain endothelial barrier: an overview of the distributional features. Curr. Med. Chem., 2007, 14, 1199-1206.

[32] Ueno, M.; Nakagawa, T.; Wu, B.; Onodera, M.; Huang, C.L.; Kusaka, T.; Araki, N.; Sakamoto, H. Transporters in the brain endothelial barrier. Curr. Med. Chem., 2010, 17, 1125-1138.

[33] Giebel, S.J.; Menicucci, G.; McGuire, P.G.; Das, A. Matrix metalloproteinases in early diabetic retinopathy and their role in alteration of the blood-retinal barrier. Lab. Invest., 2005, 85, 597-607.

[34] Fujimoto, K. Pericyte-endothelial gap junctions in developing rat cerebral capillaries: a fine structural study. Anat. Rec., 1995, 242, 562-565.

[35] Hirschi, K.K.; D'Amore, P.A. Pericytes in the microvasculature. Cardiovasc. Res., 1996, 32, 687-698.

[36] Gerhardt, H.; Betsholtz, C. Endothelial-pericyte interactions in angiogenesis. Cell. Tissue Res., 2003, 314, 1523.

[37] Hammes, H.P.; Lin, J.; Renner, O.; Shani, M.; Lundqvist, A.; Betsholtz, C.; Brownlee, M.; Deutsch, U. Pericytes and the pathogenesis of diabetic retinopathy. Diabetes, 2002, 51, 3107-3112.

[38] Lindahl, P.; Johansson, B.R.; Levéen, P.; Betsholtz, C. Pericyte loss and microaneurysm formation in PDGFB-deficient mice. Science, 1997, 277, 242-245.

[39] Hellström, M.; Kalén, M.; Lindahl, P.; Abramsson, A.; Betsholtz, C. Role of PDGF-B and PDGFR-beta in recruitment of vascular smooth muscle cells and pericytes during embryonic blood vessel formation in the mouse. Development, 1999, 126, 3047-3055.

[40] Ramsauer, M.; D'Amore, P.A. Getting Tie(2)d up in angiogenesis. J. Clin. Invest., 2002, 110, 1615-1617.

[41] Martin, A.R.; Bailie, J.R.; Robson, T.; McKeown, S.R.; Al-Assar, O.; McFarland, A.; Hirst, D.G. Retinal pericytes control expression of nitric oxide synthase and endothelin-1 in microvascular endothelial cells. Microvasc. Res., 2000, 59, 131-139.

[42] Bringmann, A.; Pannicke, T.; Grosche, J.; Francke, M.; Wiedemann, P.; Skatchkov, S.N.; Osborne, N.N.; Reichenbach, A. Müller cells in the healthy and diseased retina. Prog. Retin. Eye Res., 2006, 25, 397-424.

[43] Engerman, R.L. Pathogenesis of diabetic retinopathy. Diabetes, 1989, 38, 1203-1206.

[44] Benjamin, L.E. Glucose, VEGF-A, and diabetic complications. Am. J. Pathol., 2001, 158, 1181-1184.

[45] Frank, R.N. Diabetic retinopathy. N. Engl. J. Med., 2004, 350, 48-58.

[46] Li, W.; Liu, X.; Yanoff, M.; Cohen, S.; Ye, X. Cultured retinal capillary pericytes die by apoptosis after an abrupt fluctuation from high to low glucose levels: a comparative study with retinal capillary endothelial cells. Diabetologia, 1996, 39, 537-547.

[47] Naruse, K.; Nakamura, J.; Hamada, Y.; Nakayama, M.; Chaya, S.; Komori, T.; Kato, K.; Kasuya, Y.; Miwa, K.; Hotta, N. Aldose reductase inhibition prevents glucose-induced apoptosis in cultured bovine retinal microvascular pericytes. Exp. Eye Res., 2000, 71, 309-315.

[48] Romeo, G.; Liu, W.H.; Asnaghi, V.; Kern, T.S.; Lorenzi, M. Activation of nuclear factor-kappa B induced by diabetes and high glucose regulates a pro-apoptotic program in retinal pericytes. Diabetes, 2002, 51, $2604-2611$.

[49] Beltramo, E.; Berrone, E.; Buttiglieri, S.; Porta, M. Thiamine and benfotiamine prevent increased apoptosis in endothelial cells and pericytes cultured in high glucose. Diabetes Metab. Res. Rev., 2004, 20, 330-336.

[50] Amano, S.; Yamagishi, S.; Inagaki, Y.; Nakamura, K.; Takeuchi, M.; Inoue, H.; Imaizumi, T. Pigment epithelium-derived factor inhibits oxidative stress-induced apoptosis and dysfunction of cultured retinal pericytes. Microvasc. Res., 2005, 69, 45-55.

[51] Beltramo, E.; Nizheradze, K.; Berrone, E.; Tarallo, S.; Porta, M. Thiamine and benfotiamine prevent apoptosis induced by high glucose-conditioned extracellular matrix in human retinal pericytes. Diabetes Metab. Res. Rev., 2009, 25, 647-656. 
[52] Beltramo, E.; Berrone, E.; Tarallo, S.; Porta, M. Different apoptotic responses of human and bovine pericytes to fluctuating glucose levels and protective role of thiamine. Diabetes Metab. Res. Rev., 2009, 25, 566-576.

[53] Risso, A.; Mercuri, F.; Quagliaro, L.; Damante, G.; Ceriello; A. Intermittent high glucose enhances apoptosis in human umbilical vein endothelial cells in culture. Am. J. Physiol. Endocrinol. Metab., 2001, 281, E924-930.

[54] Quagliaro, L.; Piconi, L.; Assaloni, R.; Martinelli, L.; Motz, E.; Ceriello, A. Intermittent high glucose enhances apoptosis relate to oxidative stress in human umbilical vein endothelial cells. Diabetes, 2003, 52, 2795-2804.

[55] Piconi, L.; Quagliaro, L.; Assaloni, R.; Da Ros, R.; Maier, A.; Zuodar, G.; Ceriello, A. Constant and intermittent high glucose enhances endothelial cell apoptosis through mitochondrial superoxide overproduction. Diab. Met. Res. Rev., 2006, 22, 198-203.

[56] Ihnat, M.A.; Thorpe, J.E.; Kamat, C.D.; Szabó, C.; Green, D.E.; Warnke, L.A.; Lacza, Z.; Cselenyák, A.; Ross, K.; Shakir, S.; Piconi, L.; Kaltreider, R.C.; Ceriello, A. Reactive oxygen species mediate a cellular "memory" of high glucose stress signalling. Diabetologia, 2007, 50, 1523-1531.

[57] Bonora, E.; Muggeo, M. Postprandial blood glucose as a risk factor for cardiovascular disease in type II diabetes: the epidemiological evidence. Diabetologia, 2001, 44, 2107-2114.

[58] Shichiri, M.; Kishikawa, H.; Ohkubo, Y.; Wake, N. Long-term results of the Kumamoto study on optimal diabetes control in type 2 diabetic patients. Diabetes Care, 2000, 23 (suppl.2), B21-B29.

[59] Rassam, S.M.; Patel, V.; Kohner, E.M. The effect of experimental hypertension on retinal vascular autoregulation in humans: a mechanism for the progression of diabetic retinopathy. Exp. Physiol., 1995, 80, 53-68.

[60] Hughes, S.J.; Wall, N.; Scholfield, C.N.; McGeown, J.G.; Gardiner, T.A.; Stitt, A.W.; Curtis, T.M. Advanced glycation end product modified basement membrane attenuates endothelin-1 induced [Ca2+]i signalling and contraction in retinal microvascular pericytes. Mol. Vis., 2004, 10, 996-1004.

[61] Beltramo, E.; Berrone, E.; Giunti, S.; Gruden, G.; Cavallo Perin, P.; Porta, M. Effects of mechanical stress and high glucose on pericyte proliferation, apoptosis and contractile phenotype. Exp. Eye Res., 2006, 83, 989-994.

[62] Pugliese, G.; Tilton, R.G.; Speedy, A.; Santarelli, E.; Eades, D.M.; Province, M.A.; Kilo, C.; Sherman, W.R.; Williamson, J.R. Modulation of hemodynamic and vascular filtration changes in diabetic rats by dietary myoinositol. Diabetes, 1990, 39, 312-22.

[63] Bank, N.; Mower, P.; Aynedjian, H.S.; Wilkes, B.M.; Silverman, S. Sorbinil prevents glomerular hyperperfusion in diabetic rats. Am. J. Physiol., 1989, $256(6$ Pt 2), F1000-1006.

[64] De Vriese, A.S.; Verbeuren, T.J.; Van de Voorde, J.; Lameire, N.H. ; Vanhoutte, P.M. Endothelial dysfunction in diabetes. Br. J. Pharmacol., 2000, 130: 963-974.

[65] Beltramo, E.; Pomero, F.; Allione, A.; D’Alù, F.; Ponte, E.; Porta, M. Pericyte adhesion is impaired on extracellular matrix produced by endothelial cells in high hexose concentrations. Diabetologia, 2002, 45, 416-419

[66] Beltramo, E.; Buttiglieri, S.; Pomero, F.; Allione, A.; D’Alù, F.; Ponte, E.; Porta, M. A study of capillary pericyte viability on extracellular matrix produced by endothelial cells in high glucose. Diabetologia, 2003, 46, 409-415

[67] Hall, A.P. Review of the pericyte during angiogenesis and its role in cancer and diabetic retinopathy. Toxicol. Pathol., 2006, 34, 763-775.

[68] Cagliero, E.; Maiello, M.; Boeri, D.; Roy, S.; Lorenzi, M. Increased expression of basement membrane components in human endothelial cells cultured in high glucose. J. Clin. Invest., 1988, 82, 735-738.

[69] Cagliero, E.; Roth, T.; Roy, S.; Lorenzi, M. Characteristics and mechanisms of high-glucose-induced overexpression of basement membrane components in cultured human endothelial cells. Diabetes, 1991, 40, 102110.

[70] Roth, T.; Podestá, F.; Stepp, M.A.; Boeri, D.; Lorenzi, M. Integrin overexpression induced by high glucose and by human diabetes: potential pathway to cell dysfunction in diabetic microangiopathy. Proc. Natl. Acad. Sci. U.S.A., 1993, 90, 9640-9644.

[71] Casaroli Marano, R.P.; Preissner, K.T.; Vilaró, S. Fibronectin, laminin, vitronectin and their receptors at newly-formed capillaries in proliferative diabetic retinopathy. Exp. Eye Res., 1995, 60, 5-17.

[72] Preissner, K.T., Kanse, S.M., Hammes, H.P. Integrin chatter and vascular function in diabetic retinopathy. Horm. Metab. Res., 1997, 29, 643-645.

[73] Podestà, F.; Roth, T.; Ferrara, F.; Cagliero, E.; Lorenzi, M. Cytoskeletal changes induced by excess extracellular matrix impair endothelial cell replication. Diabetologia, 1997, 40, 879-886.

[74] Roy, S.; Nasser, S.; Yee, M.; Graves, D.T.; Roy, S. A long-term siRNA strategy regulates fibronectin overexpression and improves vascular lesions in retinas of diabetic rats. Mol. Vis., 2011, 17, 3166-3174. 
[75] Di Mario, U.; Pugliese, G. 15th Golgi lecture: from hyperglycaemia to the dysregulation of vascular remodelling in diabetes. Diabetologia, 2001, 44, 674-692.

[76] DCCT: The Diabetes Control and Complications Trial Research Group. The effect of intensive treatment of diabetes on the development and progression of long-term complications in insulin-dependent diabetes mellitus. $N$. Engl. J. Med., 1993, 329, 977-986.

[77] UK Prospective Diabetes Study Group. Intensive blood-glucose control with sulphonylureas or insulin compared with conventional treatment and risk of complications in patients with type 2 diabetes (UKPDS 33). Lancet, 1998, 352, 837-853.

[78] Ströder, K.; Unger, T.; Steckelings, U.M. The Renin-Angiotensin System in the Eye. In: Experimental Approaches to Diabetic Retinopathy; Hammes, H.P.; Porta, M. Eds.; Front Diabetes, Karger: Basel, 2010; Vol. 20, pp. 142-157.

[79] Paul, M.; Poyan Mehr, A.; Kreutz, R. Physiology of local renin-angiotensin systems. Physiol. Rev., 2006, 86, 747-803.

[80] Wagner, J.; Jan Danser, A.H.; Derkx, F.H.; de Jong, T.V.; Paul, M.; Mullins, J.J.; Schalekamp, M.A.; Ganten, D. Demonstration of renin mRNA, angiotensinogen mRNA, and angiotensin converting enzyme mRNA expression in the human eye: evidence for an intraocular renin-angiotensin system. Br. J. Ophthalmol., 1996, 80, $159-63$.

[81] Carey, R.M.; Siragy, H.M. The intrarenal renin-angiotensin system and diabetic nephropathy. Trends Endocrinol. Metab., 2003, 14, 274-281.

[82] Yamagishi, S.; Amano, S.; Inagaki, Y.; Okamoto, T.; Inoue, H.; Takeuchi, M.; Choei, H.; Sasaki, N.; Kikuchi, S. Angiotensin II-type 1 receptor interaction upregulates vascular endothelial growth factor messenger RNA levels in retinal pericytes through intracellular reactive oxygen species generation. Drugs Exp. Clin. Res., 2003, 29, 7580.

[83] Kawamura, H.; Kobayashi, M.; Li, Q.; Yamanishi, S.; Katsumura, K.; Minami, M.; Wu, D.M.; Puro, D.G. Effects of angiotensin II on the pericyte-containing microvasculature of the rat retina. J. Physiol., 2004, 561, 671683.

[84] Seshiah, P.N.; Weber, D.S.; Rocic, P.; Valppu, L.; Taniyama, Y.; Griendling, K.K. Angiotensin II stimulation of NAD(P)H oxidase activity: upstream mediators. Circ. Res., 2002, 91, 406-413.

[85] Kato, H.; Suzuki, H.; Tajima, S.; Ogata, Y.; Tominaga, T.; Sato, A.; Saruta, T. Angiotensin II stimulates collagen synthesis in cultured vascular smooth muscle cells. J. Hypertens., 1991, 9, 17-22.

[86] Ruiz-Ortega, M.; Lorenzo, O.; Rupérez, M.; König, S.; Wittig, B.; Egido, J. Angiotensin II activates nuclear transcription factor kappaB through AT(1) and AT(2) in vascular smooth muscle cells: molecular mechanisms. Circ. Res., 2000, 86, 1266-1272.

[87] Thomas, M.C.; Tikellis, C.; Burns, W.M.; Bialkowski, K.; Cao, Z.; Coughlan, M.T.; Jandeleit-Dahm, K.; Cooper, M.E.; Forbes, J.M. Interactions between renin angiotensin system and advanced glycation in the kidney. J. Am. Soc. Nephrol., 2005, 16, 2976-2984.

[88] Policha, A.; Daneshtalab, N.; Chen, L.; Dale, L.B.; Altier, C.; Khosravani, H.; Thomas, W.G.; Zamponi, G.W.; Ferguson, S.S. Role of angiotensin II type 1A receptor phosphorylation, phospholipase D, and extracellular calcium in isoform-specific protein kinase C membrane translocation responses. J. Biol. Chem., 2006, 281, 2634026349.

[89] Clements, R.S. Jr.; Morrison, A.D.; Winegrad, A.I. Polyol pathway in aorta: regulation by hormones. Science, 1969, 166, 1007-1008.

[90] Hsieh, T.J.; Fustier, P.; Zhang, S.L.; Filep, J.G.; Tang, S.S.; Ingelfinger, J.R.; Fantus, I.G.; Hamet, P.; Chan, J.S. High glucose stimulates angiotensinogen gene expression and cell hypertrophy via activation of the hexosamine biosynthesis pathway in rat kidney proximal tubular cells. Endocrinology, 2003, 144, 4338-4349.

[91] Cao, Z.; Cooper, M.E.; Wu, L.L.; Cox, A.J.; Jandeleit-Dahm, K.; Kelly, D.J.; Gilbert, R.E. Blockade of the renin-angiotensin and endothelin systems on progressive renal injury. Hypertension, 2000, 36, 561-568.

[92] Horio, N.; Horiguchi, M. Retinal blood flow and macular edema after radial optic neurotomy for central retinal vein occlusion. Am. J. Ophthalmol., 2006, 141, 31-34.

[93] Zhang, J.Z.; Xi, X.; Gao, L.; Kern, T.S. Captopril inhibits capillary degeneration in the early stages of diabetic retinopathy. Curr. Eye Res., 2007, 32, 883-888

[94] Chaturvedi, N.; Sjølie, A.K.; Stephenson, J.M.; Abrahamian, H.; Keipes, M.; Castellarin, A.; RoguljaPepeonik, Z.; Fuller, J.H. Effect of lisinopril on progression of retinopathy in normotensive people with type 1 
diabetes. The EUCLID Study Group. EURODIAB Controlled Trial of Lisinopril in Insulin-Dependent Diabetes Mellitus. Lancet, 1998, 351, 28-31.

[95] Chaturvedi, N.; Porta, M.; Klein, R.; Orchard, T.; Fuller, J.; Parving, H.H.; Bilous, R.; Sjølie, A.K., for the DIRECT Programme Study Group. Effect of candesartan on prevention (DIRECT-Prevent 1) and progression (DIRECT-Protect 1) of retinopathy in type 1 diabetes: randomised, placebo-controlled trials. Lancet, 2008, 372, 1394-1402.

[96] Sjølie, A.K.; Klein, R.; Porta, M.; Orchard, T.; Fuller, J.; Parving, H.H.; Bilous, R.; Chaturvedi, N., for the DIRECT Programme Study Group. Effect of candesartan on progression and regression of retinopathy in type 2 diabetes (DIRECT-Protect 2): a randomised placebo-controlled trial. Lancet, 2008, 372, 1385-1393.

[97] Nishikawa, T.; Edelstein, D.; Brownlee, M. The missing link: A single unifying mechanism for diabetic complications. Kidney Int., 2000, 58, S26-S30.

[98] Brignardello, E.; Beltramo, E.; Molinatti, P.A.; Aragno, M.; Gatto, V.; Tamagno, E.; Danni, O.; Porta, M.; Boccuzzi, G. Dehydroepiandrosterone protects bovine retinal capillary pericytes against glucose toxicity. $J$. Endocrinol., 1998, 158, 21-26.

[99] Podestà, F.; Romeo, G.; Liu, W.H.; Krajewski, S.; Reed, J.C.; Gerhardinger, C.; Lorenzi, M. Bax is increased in the retina of diabetic subjects and is associated with pericyte apoptosis in vivo and in vitro. Am. J. Pathol., 2000, 156, 1025-1032.

[100] Van Ballegooie, E.; Hooymans, J.M.; Timmerman, Z.; Reitsma, W.D.; Sluiter, W.J.; Schweitzer, N.M.; Doorenbos, H. Rapid deterioration of diabetic retinopathy during treatment with continuous subcutaneous insulin infusion. Diabetes Care, 1984, 7, 236-242.

[101] Dandona, P.; Bolger, J.P.; Boag, F.; Fonesca, V.; Abrams, J.D. Rapid development and progression of proliferative retinopathy after strict diabetic control. Br. Med. J., 1985, 290, 885-896.

[102] Dahl-Jorgensen, K.; Brinchmann-Hansen, O.; Hanssen, K.F.; Sandvik, L.; Aagenages, O. Rapid tightening of blood glucose levels leads to transient deterioration of retinopathy in insulin dependent diabetes mellitus. $B r$. Med. J., 1985, 290, 811-815.

[103] Engerman, R.L.; Kern, T.S. Progression of incipient diabetic retinopathy during good glycaemic control. Diabetes, 1987, 36, 808-812.

[104] Beltramo, E.; Berrone, E.; Tarallo, S.; Porta, M. Effects of thiamine and benfotiamine on intracellular glucose metabolism and relevance in the prevention of diabetic complications. Acta Diabetol., 2008, 45, 131-141.

[105] Williamson, J.R.; Chang, K.; Frangos, M.; Hasan, K.S.; Ido, Y.; Kawamura, T.; Nyengaard, J.R.; Van Den Enden, M.; Kilo, C.; Tilton, R.G. Hyperglycemic pseudoypoxia and diabetic complications. Diabetes, 1993, 42, 801-813.

[106] Lee, A.Y.; Chung, S.S. Contributions of polyol pathway to oxidative stress in diabetic cataract. FASEB J., 1999, 13, 23-30.

[107] Brownlee, M. Biochemistry and molecular cell biology of diabetic complications. Nature, 2001, 414, 813-820.

[108] Baynes, J.W. Role of oxidative stress in development of complications in diabetes. Diabetes, 1991, 40, 405412.

[109] Giardino, I.; Edelstein, D.; Brownlee, M. Nonenzymatic glycosylation in vitro and in bovine endothelial cells alters basic fibroblast growth factor activity. A model for intracellular glycosylation in diabetes. J. Clin. Invest. 1994, 94, 110-117.

[110] Charonis, A.S.; Reger, L.A.; Dege, J.E.; Kouzi-Koliakos, K.; Furcht, L.T.; Wohlhueter, R.M.; Tsilibary, E.C. Laminin alterations after in vitro nonenzymatic glycosylation. Diabetes, 1990, 39, 807-814.

[111] Doi, T.; Vlassara, H.; Kirstein, M.; Yamada, Y.; Striker, G.E.; Striker, L.J. Receptor-specific increase in extracellular matrix production in mouse mesangial cells by advanced glycosylation end products is mediated via platelet-derived growth factor. Proc Natl Acad Sci U.S.A., 1992, 89, 2873-2877.

[112] Schmidt, A.M.; Hori, O.; Chen, J.X.; Li, J.F.; Crandall, J.; Zhang, J.; Cao, R.; Yan, S.D.; Brett, J.; Stern, D. Advanced glycation endproducts interacting with their endothelial receptor induce expression of vascular cell adhesion molecule-1 (VCAM-1) in cultured human endothelial cells and in mice. A potential mechanism for the accelerated vasculopathy of diabetes. J. Clin. Invest., 1995, 96, 1395-1403.

[113] Koya, D.; King, G.L. Protein kinase C activation and the development of diabetic complications. Diabetes, 1998, $47,859-866$. 
[114] Koya, D.; Jirousek, M.R.; Lin, Y.W.; Ishii, H.; Kuboki, K.; King, G.L. Characterization of protein kinase C beta isoform activation on the gene expression of transforming growth factor-beta, extracellular matrix components, and prostanoids in the glomeruli of diabetic rats. J. Clin. Invest., 1997, 100, 115-126.

[115] Nishikawa, T.; Edelstein, D.; Du, X.L.; Yamagishi, S.; Matsumura, T.; Kaneda, Y.; Yorek, M.A.; Beebe, D.; Oates, P.J.; Hammes, H.P.; Giardino, I.; Brownlee, M. Normalizing mitochondrial superoxide production blocks three pathways of hyperglycaemic damage. Nature, 2000, 404,787-790.

[116] Schleicher, E.D.; Weigert, C. Role of the hexosamine biosyntetic pathway in diabetic nephropathy. Kidney Int., 2000, 77, S13-18.

[117] Du, X.L.; Edelstein, D.; Rossetti, L.; Fantus, I.G.; Goldberg, H.; Ziyadeh, F.; Wu, J.; Brownlee, M. Hyperglycemia-induced mitochondrial superoxide overproduction activates the hexosamine pathway and induces plasminogen activator inhibitor-1 expression by increasing Sp1 glycosylation. Proc. Natl. Acad. Sci. U.S.A., 2000, 97, 12222-12226.

[118] Du, X.L.; Matsumura, T.; Edelstein, D.; Rossetti, L.; Zsengellér, Z.; Szabó, C.; Brownlee, M. Inhibition of GAPDH activity by poly(ADP-ribose) polymerase activates three major pathways of hyperglycemic damage in endothelial cells. J. Clin. Invest., 2003, 112, 1049-1057.

[119] Wu, M.; Chen, Y.; Wilson, K.; Chirindel, A.; Ihnat, M.A.; Yu, Y.; Boulton, M.E.; Szweda, L.I.; Ma, J.X.; Lyons T.J. Intraretinal leakage and oxidation of LDL in diabetic retinopathy. Invest. Ophthalmol. Vis. Sci., 2008, 49, 2679-2685.

[120] Fu, D.; Wu, M.; Zhang, J.; Du, M.; Yang, S.; Hammad, S.M.; Wilson, K.; Chen, J.; Lyons, T.J. Mechanisms of modified LDL-induced pericyte loss and retinal injury in diabetic retinopathy. Diabetologia, 2012, 55, 3128-3140.

[121] Pfister, F.; Feng, Y.; vom Hagen, F.; Hoffmann, S.; Molema, G.; Hillebrands, J.L.; Shani, M.; Deutsch, U.; Hammes, H.P. Pericyte migration: a novel mechanism of pericyte loss in experimental diabetic retinopathy. Diabetes, 2008, 57, 2495-2502.

[122] Trudeau, K.; Molina, A.J.; Roy, S. High glucose induces mitochondrial morphology and metabolic changes in retinal pericytes. Invest. Ophthalmol. Vis. Sci., 2011, 52, 8657-8664.

[123] Tu, Z.; Li, Y.; Smith, D.S.; Sheibani, N.; Huang, S.; Kern, T.; Lin, F. Retinal pericytes inhibit activated T cell proliferation. Invest. Ophthalmol. Vis. Sci., 2011, 52, 9005-9010.

[124] Li, Y.; Smith, D.; Li, Q.; Sheibani, N.; Huang, S.; Kern, T.; Nagaraj, R.H.; Lin, F. Antibody-mediated retinal pericyte injury: implications for diabetic retinopathy. Invest. Ophthalmol. Vis. Sci., 2012, 53, 5520-5526. 